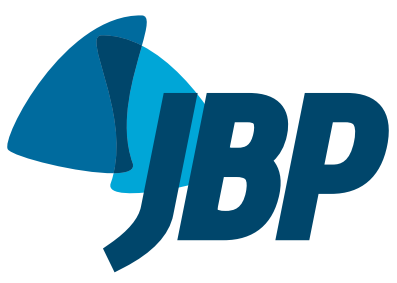

\section{Giant pulmonary artery aneurysm in a patient with schistosomiasis-associated pulmonary arterial hypertension}

\author{
Francisca Gavilanes,a, Bruna Piloto ${ }^{1, b}$, Caio Julio Cesar Fernandes
}

Dilatation of the pulmonary artery is a feature that is commonly present in pulmonary arterial hypertension, being even more pronounced in cases of schistosomiasisassociated pulmonary arterial hypertension. ${ }^{(1)}$ Aneurysmal dilatations of the pulmonary artery, although less common, have a much greater potential for complications, causing anything from pulmonary artery dissection ${ }^{(2)}$ to extrinsic compression of other regions.

We report the case of a 38-year-old male patient with a $>10$-year history of schistosomiasis-associated pulmonary arterial hypertension, with compression of the aorta and coronary artery by a giant pulmonary artery aneurysm. Mean pulmonary artery pressure was $33 \mathrm{mmHg}$, pulmonary capillary pressure was $10 \mathrm{mmHg}$, and cardiac output was $6.9 \mathrm{~L} / \mathrm{min}$, without evidence of congenital heart disease or lung disease. The patient reported palpitations, dyspnea (categorized as functional class IV), and syncope on exertion. Chest X-ray and chest $C T$ angiography showed a giant pulmonary artery aneurysm (Figures $1 \mathrm{~A}$ and $1 \mathrm{~B}$ ), without evidence of thromboembolism but with calcifications in the main branches of the pulmonary artery, together with partial compression of the aorta and trunk of the left coronary artery (Figures $1 \mathrm{C}$ and 1D). Little is known about the dynamic behavior of such large vascular dilatations, ${ }^{(3)}$ and their potential for complications should always be considered, especially for patients in whom the symptoms are disproportionate to the hemodynamic impairment.

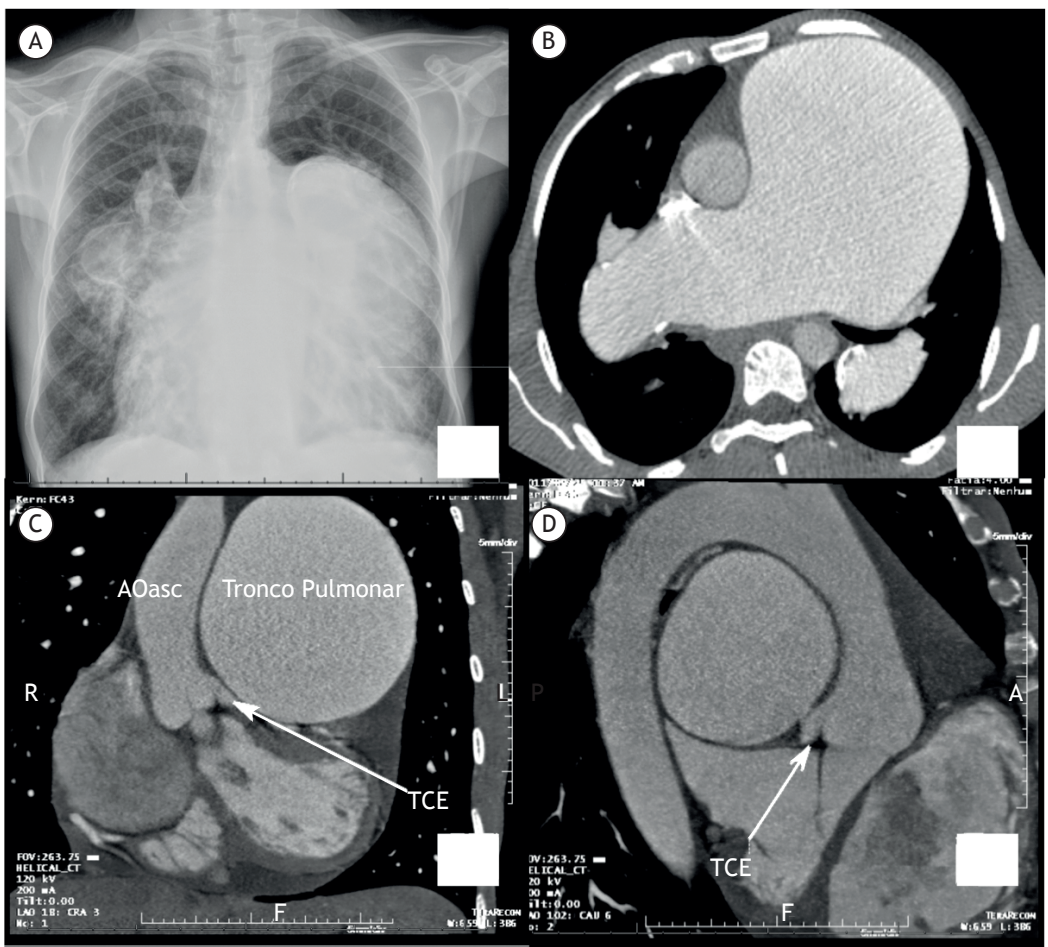

Figure 1. In A, chest X-ray; in B, chest CT scan showing aneurysmal dilatation of the pulmonary artery; and in C and $D, C T$ image reconstruction showing extrinsic compression of the ascending aorta and (white arrows) by dilatation of the pulmonary artery. Designations in Portuguese: TCE, trunk of the left coronary artery; Tronco Pulmonar: pulmonary trunk; and AOasc: ascending aorta.

\title{
REFERENCES
}

1. Hoette S, Figueiredo C, Dias B, Alves JL Jr, Gavilanes F, Prada LF et al. Pulmonary artery enlargement in schistosomiasis associated pulmonary arterial hypertension. BMC Pulm Med. 2015;15:118. https:// doi.org/10.1186/s12890-015-0115-y

2. Corrêa Rde A, Silva LC, Rezende CJ, Bernardes RC, Prata TA, Silva $\mathrm{HL}$. Pulmonary hypertension and pulmonary artery dissection. J
Bras Pneumol. 2013;39(2):238-41. https://doi.org/10.1590/S180637132013000200016

3. Vonk-Noordegraaf A, Souza R. Cardiac magnetic resonance imaging: What can it add to our knowledge of the right ventricle in pulmonary arterial hypertension? Am J Cardiol. 2012;110(6 Suppl):25S-31S. https:// doi.org/10.1016/j.amjcard.2012.06.013 